\title{
First-response treatment after out-of- hospital cardiac arrest: a survey of current practices across 29 countries in Europe
}

Iris Oving ${ }^{1}$, Siobhan Masterson², Ingvild B.M. Tjelmeland ${ }^{3}$, Martin Jonsson ${ }^{4}$, Federico Semeraro ${ }^{5}$, Mattias Ringh ${ }^{4}$, Anatolij Truhlar ${ }^{6}$, Diana Cimpoesu ${ }^{7}$, Fredrik Folke ${ }^{8,9}$, Stefanie G. Beesems ${ }^{1}$, Rudolph W. Koster ${ }^{1}$, Hanno L. Tan ${ }^{1,10^{*}}$, Marieke T. Blom ${ }^{1}$ and for the ESCAPE-NET Investigators

\begin{abstract}
Background: In Europe, survival rates after out-of-hospital cardiac arrest (OHCA) vary widely. Presence/absence and differences in implementation of systems dispatching First Responders (FR) in order to arrive before Emergency Medical Services (EMS) may contribute to this variation. A comprehensive overview of the different types of FRsystems used across Europe is lacking.

Methods: A mixed-method survey and information retrieved from national resuscitation councils and national EMS services were used as a basis for an inventory. The survey was sent to 51 OHCA experts across 29 European countries.

Results: Forty-seven (92\%) OHCA experts from 29 countries responded to the survey. More than half of European countries had at least one region with a FR-system. Four categories of FR types were identified: (1) firefighters (professional/voluntary); (2) police officers; (3) citizen-responders; (4) others including off-duty EMS personnel (nurses, medical doctors), taxi drivers. Three main roles for FRs were identified: (a) complementary to EMS; (b) part of EMS; (c) instead of EMS. A wide variation in FR-systems was observed, both between and within countries.

Conclusions: Policies relating to FRs are commonly implemented on a regional level, leading to a wide variation in FR-systems between and within countries. Future research should focus on identifying the FR-systems that most strongly influence survival. The large variation in local circumstances across regions suggests that it is unlikely that there will be a 'one-size fits all' FR-system for Europe, but examining the role of FRs in the Chain of Survival is likely to become an increasingly important aspect of OHCA research.
\end{abstract}

Keywords: First responders, Out-of-hospital cardiac arrest, Cardiopulmonary resuscitation, Europe, ESCAPE-NET

\section{Introduction}

Out-of-hospital cardiac arrest (OHCA) is lethal within minutes of collapse if left untreated, and the majority of OHCA patients die before hospital admission [1, 2]. If early cardiopulmonary resuscitation (CPR) is provided, survival rate increases [3, 4]. In particular, presence of shockable rhythm is an important determinant of

\footnotetext{
* Correspondence: h.l.tan@amc.nl

${ }^{1}$ Department of Clinical and Experimental Cardiology, Heart Center, Amsterdam Cardiovascular Sciences, Amsterdam UMC, Department of Cardiology, Heart Center, Academic Medical Center, University of

Amsterdam, Meibergdreef 9, 1105, AZ, Amsterdam, The Netherlands

${ }^{10}$ Netherlands Heart Institute, Utrecht, The Netherlands

Full list of author information is available at the end of the article
}

survival, and OHCA patients who are found with a shockable initial rhythm are more likely to survive if they are defibrillated with an automated external defibrillator (AED) [5]. However, many OHCA patients are not found in a shockable rhythm due to prolonged emergency medical services (EMS) response times, particularly in residential areas where most OHCAs occur [68]. When CPR is started quickly after collapse, the length of time that a shockable rhythm persists may be extended [9], thus prolonging the opportunity for successful defibrillation. Identifying and implementing systems that increase the likelihood of immediate CPR provision and rapid defibrillation are vital to improving

(c) The Author(s). 2019 Open Access This article is distributed under the terms of the Creative Commons Attribution 4.0 International License (http://creativecommons.org/licenses/by/4.0/), which permits unrestricted use, distribution, and 
survival. The deployment of First Responders (FRs) is one method that has been developed in order to meet this challenge.

FR-systems have been implemented differently across Europe. Some countries have expanded the traditional EMS response with dispatch of CPR trained firefighters and police officers equipped with AEDs. Research has shown that the introduction of these types of dispatched FRs led to shorter response times [10], and increased 30 day survival [11, 12]. Dispatch of trained citizen-FRs may also be successful in reducing response time [13], time to initiation of CPR $[14,15]$, time to defibrillation [16], and overall survival [17].

Survival rates after OHCA vary widely between regions across Europe [2] and the presence or absence of FRsystems, and differences in their implementation, may contribute to this variation. For instance, FRs may be less effective when they are inefficiently deployed and/or time from collapse to initiation of CPR is prolonged when the technology used for FR dispatch is suboptimal [15]. In addition, differences in FR skill sets may contribute, e.g., level of resuscitation training, available equipment, and experience in coping with emergency situations.

Survival rates after OHCA may increase across Europe if FR-systems are optimized. Similarly, optimization efforts may benefit from past experiences in FR implementation across Europe. However, to date, no comprehensive inventory of the different types of dispatched FR-systems used across Europe exists. Additionally, while the most recent European Resuscitation Guidelines emphasise the importance of community response in saving lives [18], the extent to which establishment of FR-systems has been adopted as national policy across Europe is unknown. Therefore, the aim of this paper is to create an inventory of dispatched FR-systems across Europe, and to determine whether countries have a national policy regarding FRsystems. This will serve as a basis to highlight key differences in order to ultimately optimise FR-systems across Europe.

\section{Methods}

\section{Design and set up}

This research was conducted as part of the ESCAPENET project that aims to discover the causes and best treatments of OHCA [19]. A mixed-method survey was combined with information retrieved from national resuscitation councils and national EMS services as a basis for an inventory.

\section{Survey and information gathering}

The content of the survey was determined after several meetings with an expert panel, consisting of five experts in the field of OHCA (three cardiologists, one EMSconsultant and one intensive care nurse; initials: IT, RK,
AT, FS, and MR) in Europe. The survey was built by Dutch researchers and finalised after a pilot carried out by Amsterdam Resuscitation Studies (ARREST) [20] researchers.

The survey was sent to 51 OHCA professionals across 29 European countries between August and November 2018 (Additional file 1: Supplementary 1a). An OHCA professional was defined as a European Resuscitation Council (ERC) or ESCAPE-NET member with a long working experience ( $\geq 5$ years) in the field of OHCA and, in particular, in prehospital resuscitation strategies. OHCA professionals were recruited during the ESCAPENET [19] and EuReCa [2] sessions at the ERC Congress in Bologna, 2018 (additional file 1: Supplementary 1a). Informed consent for using the contact details of the participants was sought and provided. A second attempt was made to get non-responding survey participants to take part within three weeks. All survey results were validated with the respondents before results were finalised.

In addition, data on national policies regarding FRs was sought from national resuscitation councils (or national EMS services where no council existed). If no response from a national council was received within three weeks, other national experts in the field of OHCA were consulted. Similar to the survey respondents, national experts had a long working experience ( $\geq 5$ years) in the field of OHCA and were identified using the ERC or ESCAPE-NET network. Where possible, answers from survey respondents and national resuscitation councils were cross checked.

\section{Definitions}

For the purposes of this study, EMS and FRs were defined as follows:

\section{Emergency medical services (EMS)}

Emergency Medical Services included on-duty emergency medical personnel who were dispatched by a dispatch centre to provide acute medical care and to transport the patient to a hospital equipped to provide acute care.

\section{First responder (FR)}

First Responders were defined as all individuals who were dispatched by a dispatch centre to attend OHCA events and initiate early CPR. FRs potentially included firefighters and police officers (traditional FRs) [21, 22], off-duty EMS staff and citizen-responders. An extensive description of EMS and FRs is provided in Additional file 1: Supplementary $1 \mathrm{~b}$.

\section{FR-system}

The availability of dispatched FRs was determined for each country and/or region. A FR-system was defined as 
nationwide when it covered $\geq 50 \%$ of the country. The FR-system was described and characteristics were assessed (by examining each individual type of FR, as part of the FR-system). Characteristics included: recruitment and activation methods, role on scene, equipment, CPR training and frequency of training, registration, feedback, financial support, and emotional support. An extensive description of all characteristics is provided in Additional file 1: Supplementary 1c.

\section{Results}

The response rate to the survey was $92 \%$ (47/51); information was obtained from 29 countries. For the specific questions on national policy, the response rate from national resuscitation councils was $62 \%(16 / 26$; in 26 of the 29 studied countries, a national resuscitation council existed). This rate increased to $77 \%(20 / 26)$ after consulting other experts.

\section{Types and roles of FRs in Europe}

First responders were categorised post-hoc into four main types:

1) Firefighters (professional and/or voluntary) (Fig. 1a)

2) Citizen-responders (Fig. 1b)

3) Police officers (Fig. 1c)

4) Others, i.e., all responders that could not be categorized into firefighters, citizen-responders, police officers, (e.g., off-duty EMS personnel, nurses or medical doctors, and taxi drivers).

The survey identified three main roles for FRs in the event of OHCA:
1) Complementary to the statutory EMS response;

2) Part of the statutory EMS response;

3) Instead of EMS.

More than half (19 of 29) of European countries or regions thereof had FR-systems (Fig. 2a). Such FR-systems were implemented nationwide in 16 countries, and regionally in 3 countries. In 14 countries, the FR-systems acted complementary to the statutory EMS response, while in one country FRs were part of the EMS response (France), and in another, FRs substituted the EMS (remote areas in Iceland). In 10 of 29 countries there was no dispatched FR-system (Fig. 2b).

\section{Variation in first responder-systems nationally and regionally}

Variation in the type of FR-systems was observed both between and within countries. FR-systems with one FR type existed nationwide in 8 countries and regionally in 9 countries. FR-systems with two FR types existed regionally in eight countries. FR-systems including three or four FR types existed nationwide in 6 countries and regionally in 2 countries (Fig. 2a, Additional file 1: Supplementary 2).

\section{Characteristics of first responder-systems}

Next, we analysed the characteristics of the FR types in more detail. Tables 1, 2 and 3 list the characteristics of firefighters, citizen-responders and police officers; Additional file 1: Table S1 lists the characteristics of the "other FRs". A summarised description is provided below.

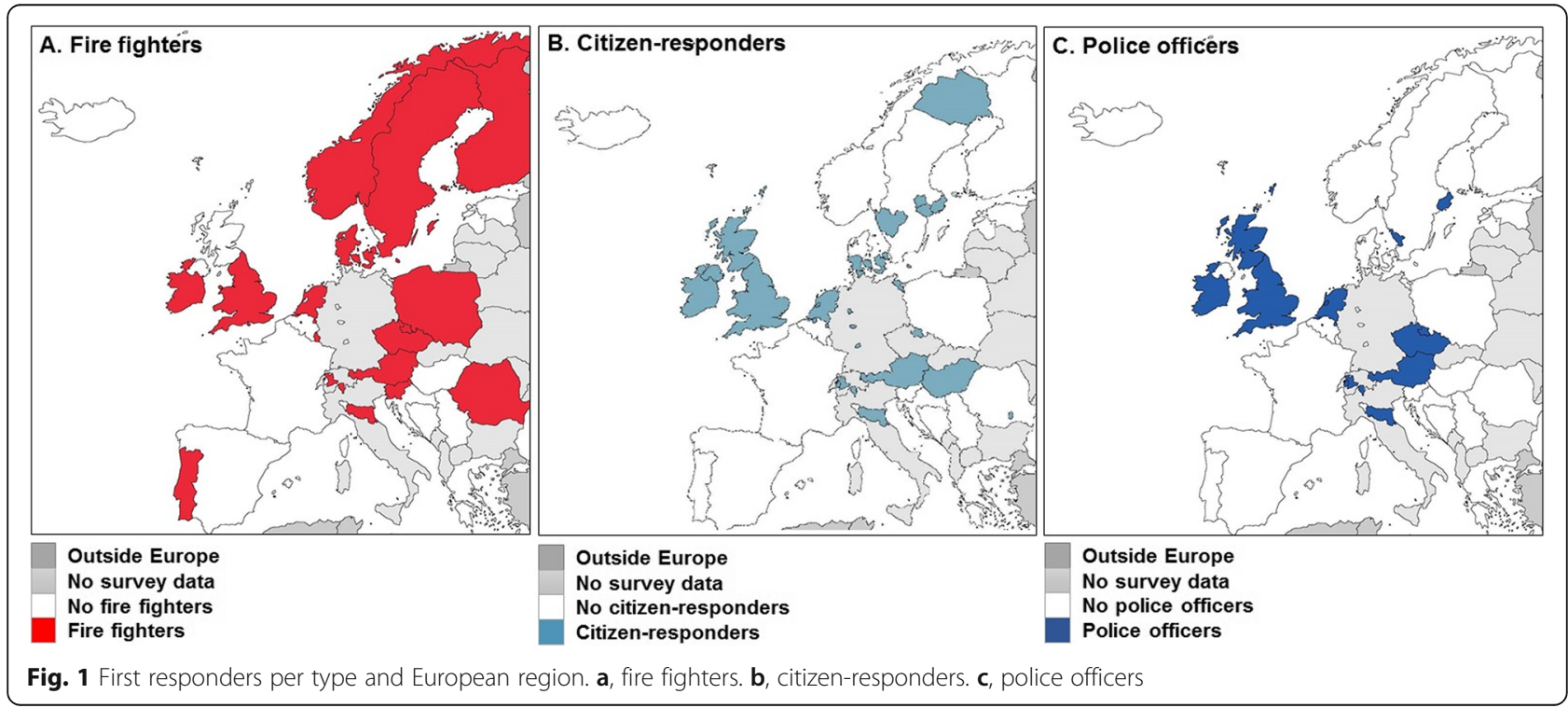



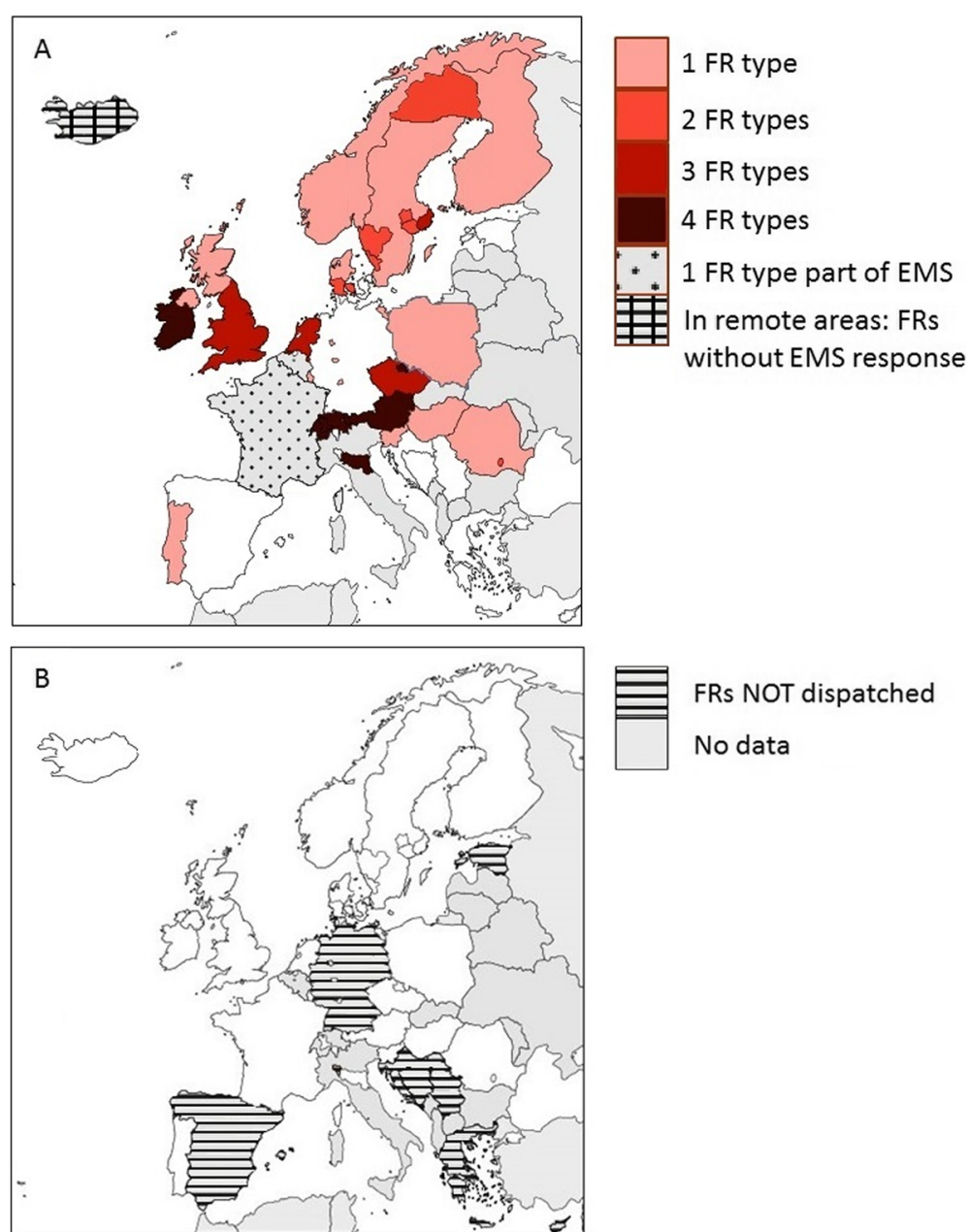

FRs NOT dispatched

No data

Fig. 2 Overview of first responder systems in Europe. a, overview of different types of dispatched first responder systems dispatched in the event of an out-of-hospital cardiac arrest, in Europe. The number of first responder refers to the number of first responders dispatched complementary to the statutory Emergency Medical Services. b, overview of regions/countries without dispatch of first responders after an out-of-hospital cardiac arrest, in Europe. Abbreviations: FRs, First responders, EMS, Emergency Medical Services

\section{Response characteristics: availability and alerts}

Different methods were used to alert FRs. For firefighters and police officers, a standard communication system is often used. A smaller proportion of regions used a dedicated mobile phone alert (Tables 1 and 3).

Citizen-responders are dispatched using a dedicated mobile phone alert in all but one region (in which only the standard communication system is used). While firefighters and police officers tend to be available on a 24/7 basis, this is not the case for all FR types (Table 2).

In several countries, there is an age threshold to be dispatched as a citizen-responder (e.g., $\geq 16$ or $\geq 18$ years). Also, in a few countries there is no dispatch of citizen-responders to children (e.g., < 8 years).

\section{Equipment}

In every country and region, FRs either carry an AED, or are directed by the dispatch centre to the nearest publicly accessible AED. Safety jackets, pocket masks, mobile phones, and rescuer kits are generally part of the equipment.

\section{Training and registration}

In most European regions, CPR training is required and checked before FRs can be dispatched, except for citizenresponders in Denmark (in two regions: Capital region and Central region) and Hungary. The frequency of mandatory CPR training differed between countries, particularly for citizen-responders (varying from monthly training to none). In Italy, untrained citizens are by law not allowed to use an AED, but can perform CPR.

Citizen-responders are most commonly registered in online databases such as HartslagNu (the Netherlands), MOMENTUM (Switzerland), O2 SOS (Czech Republic), DAE respondER (Italy). In some countries, including Ireland and Scotland, registration is managed by the 


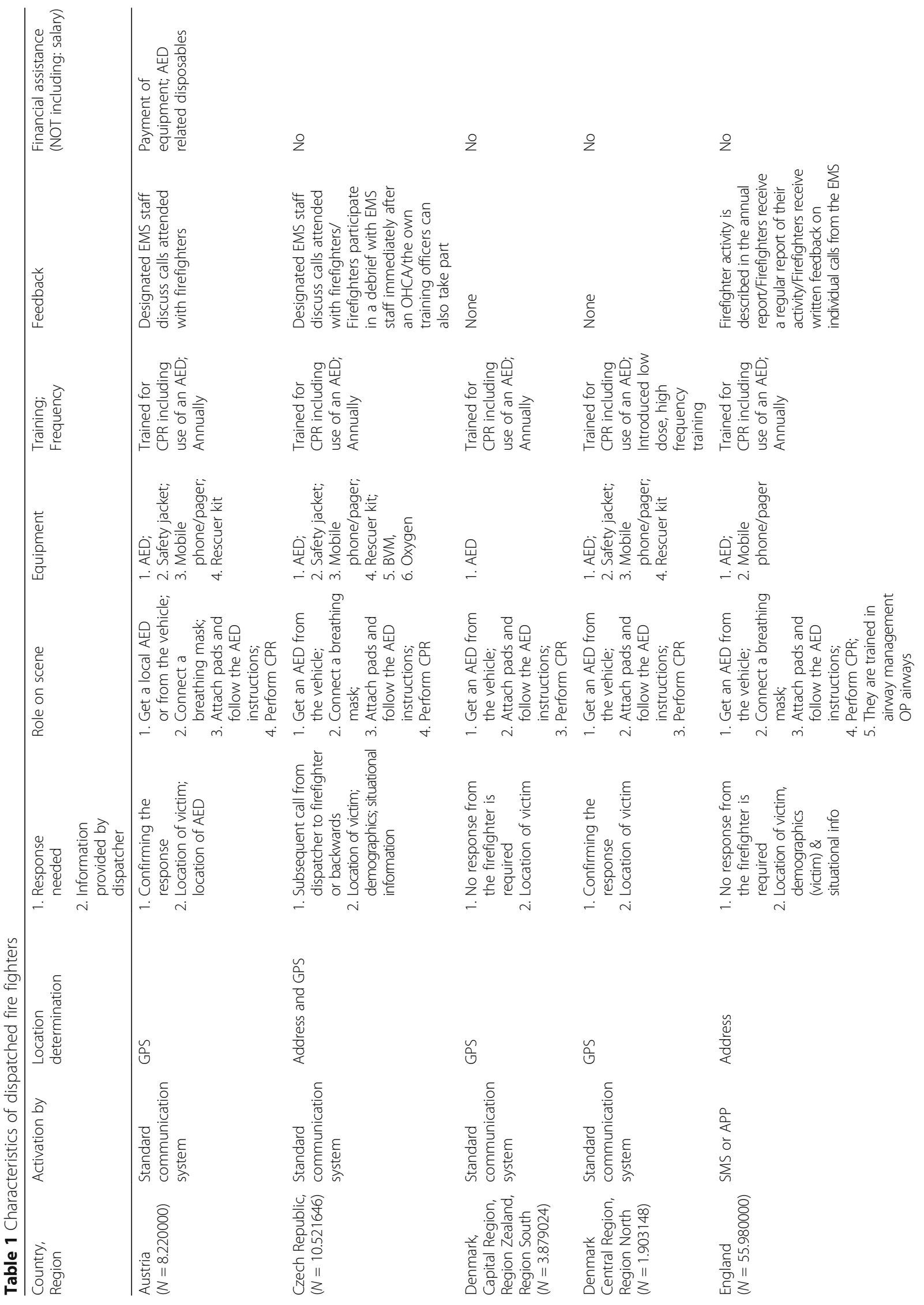




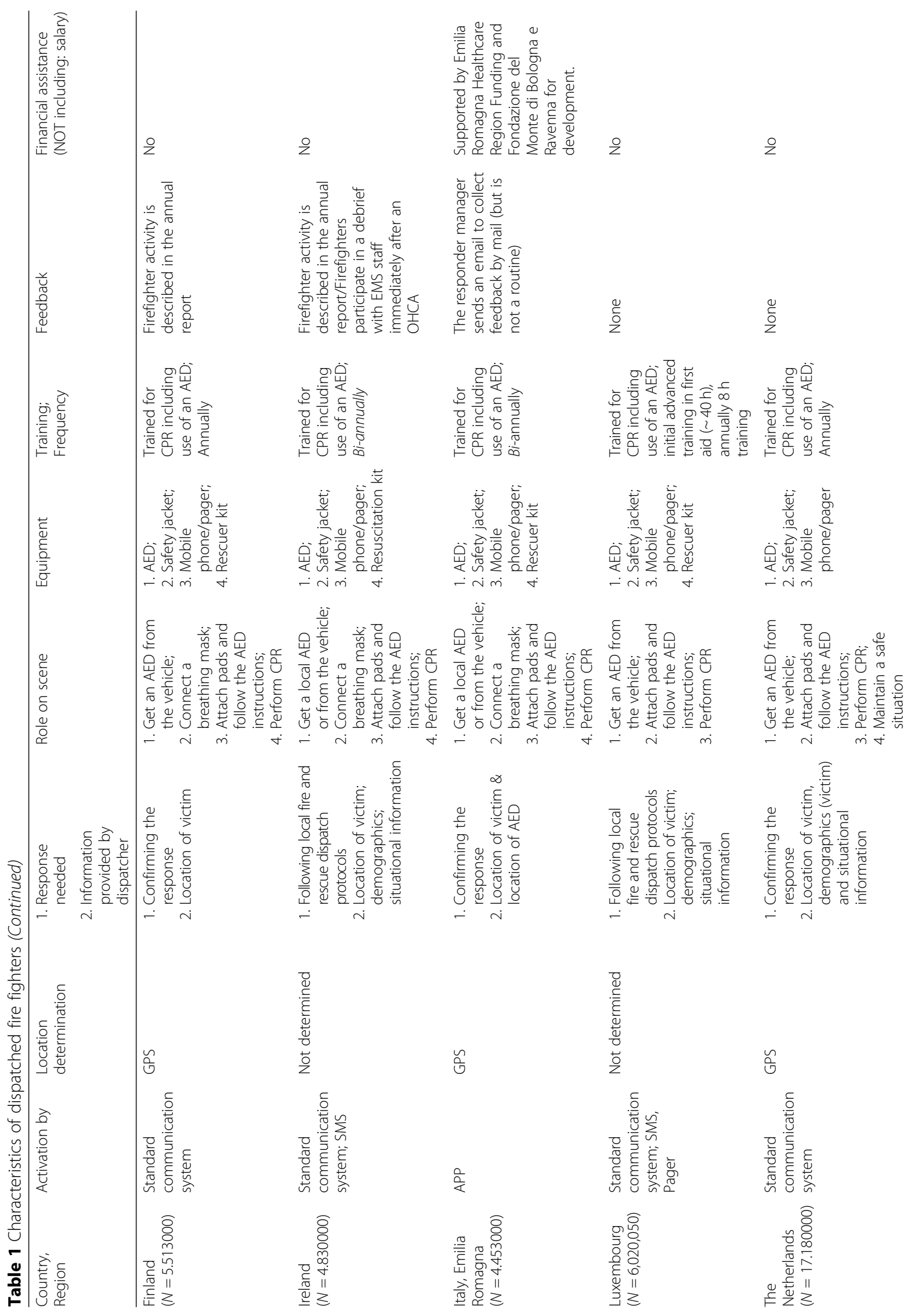




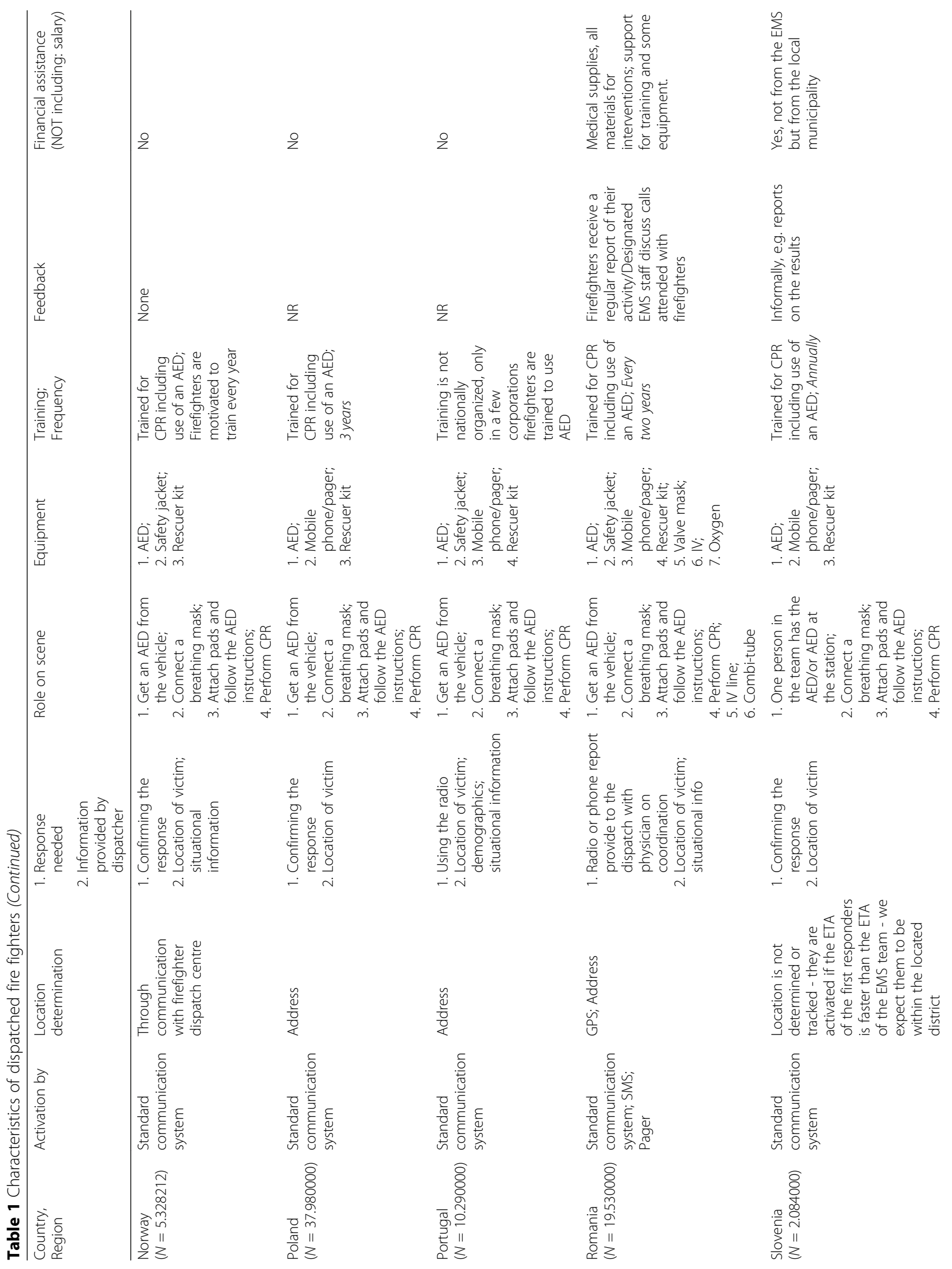




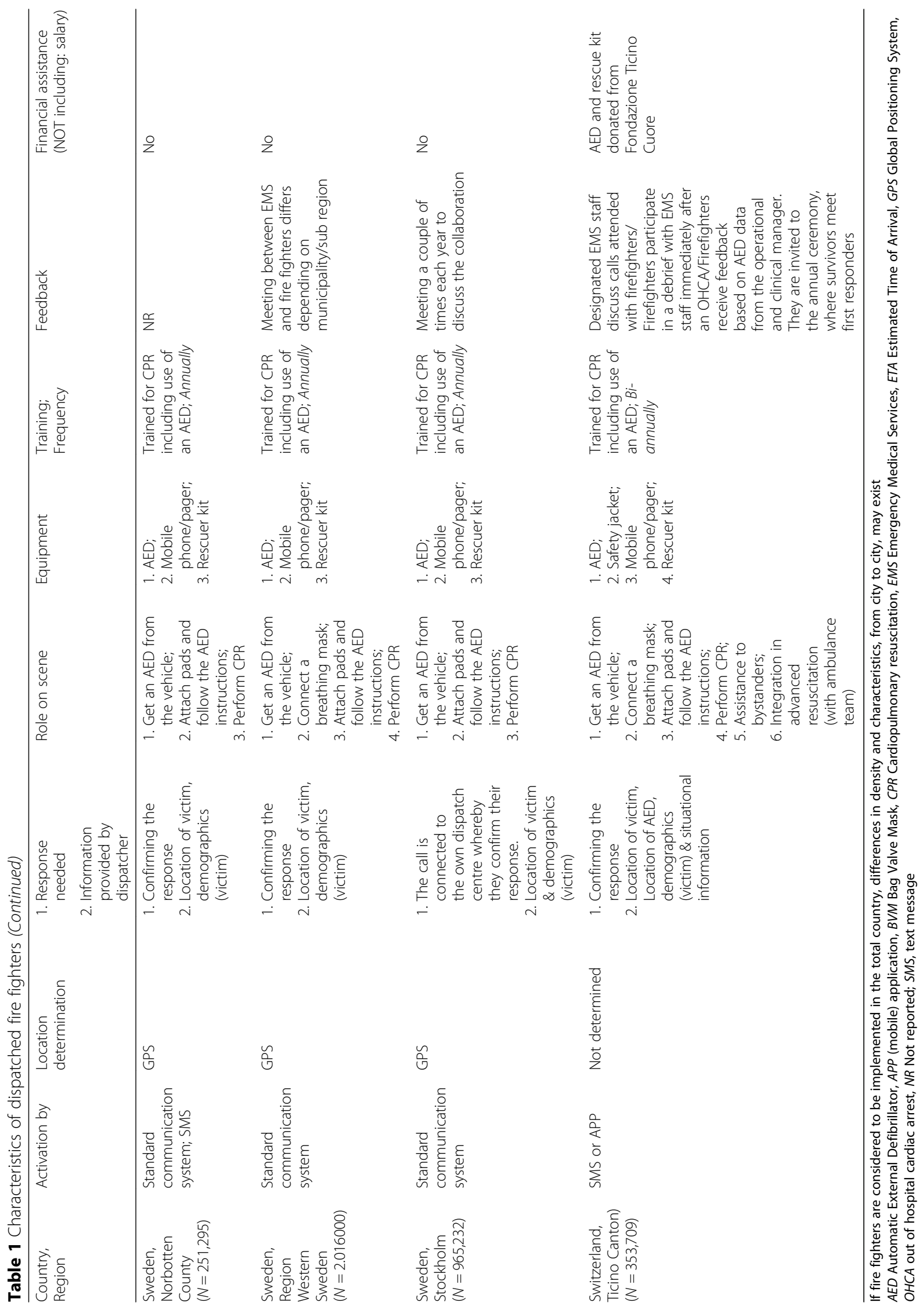




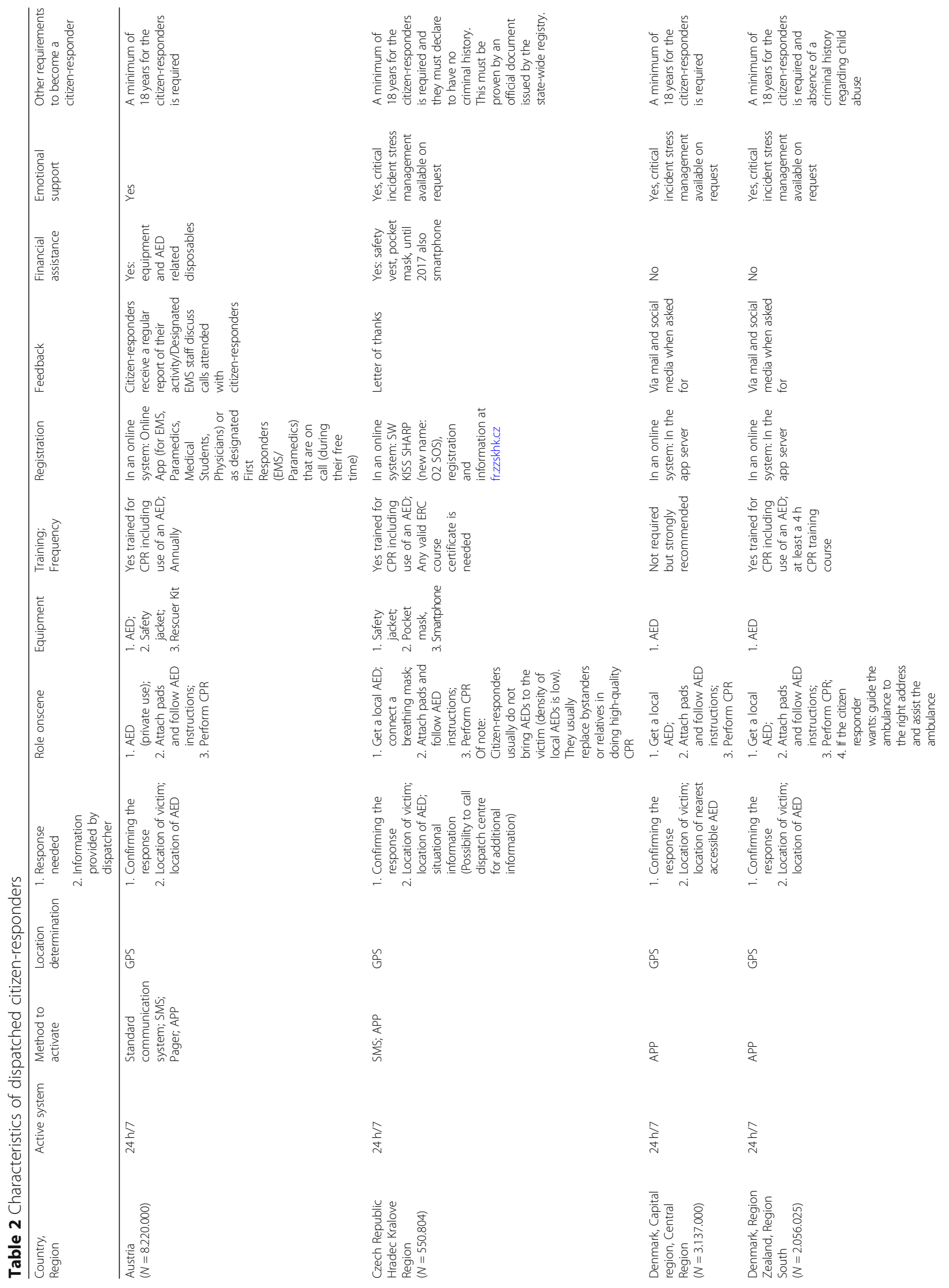




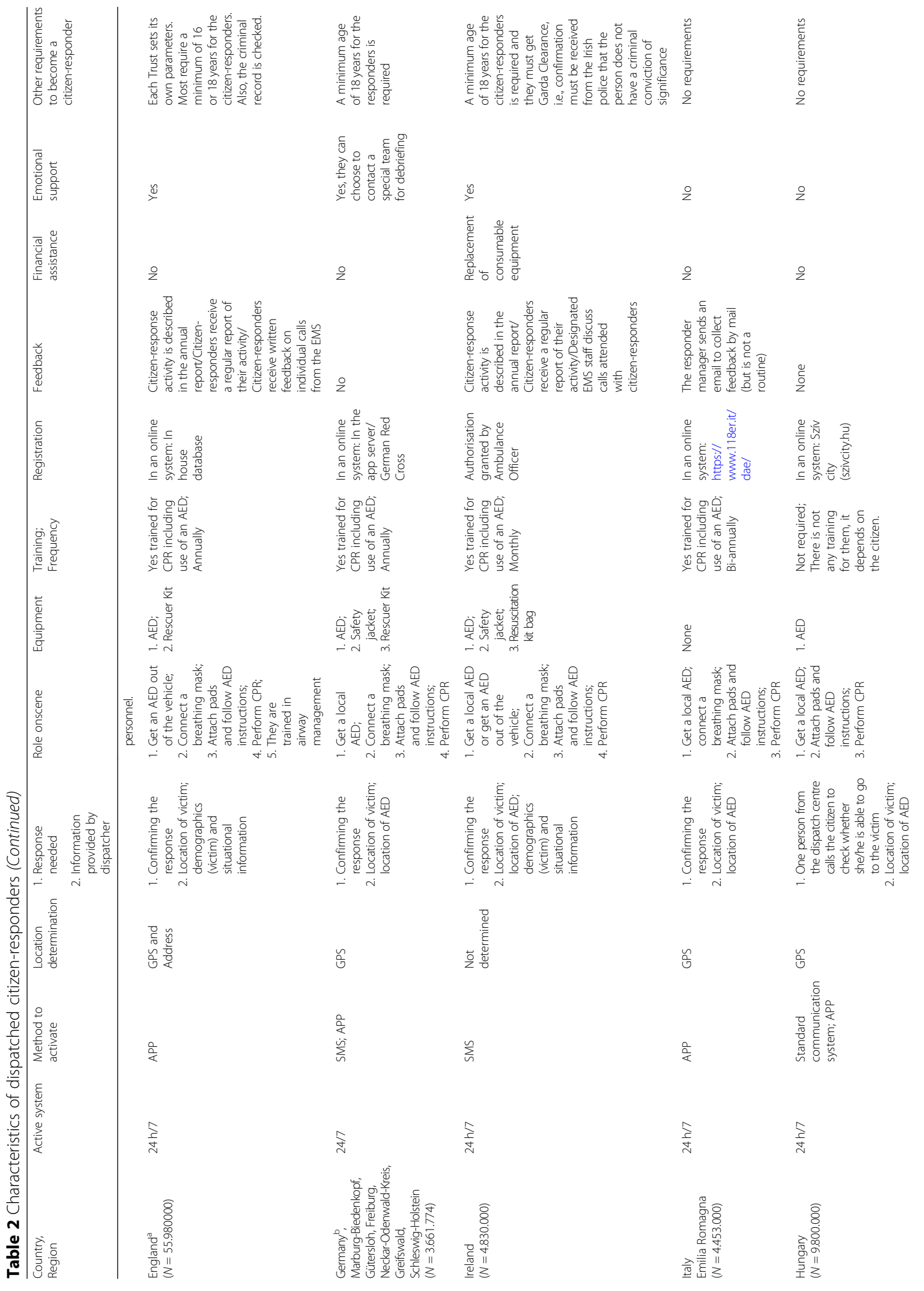




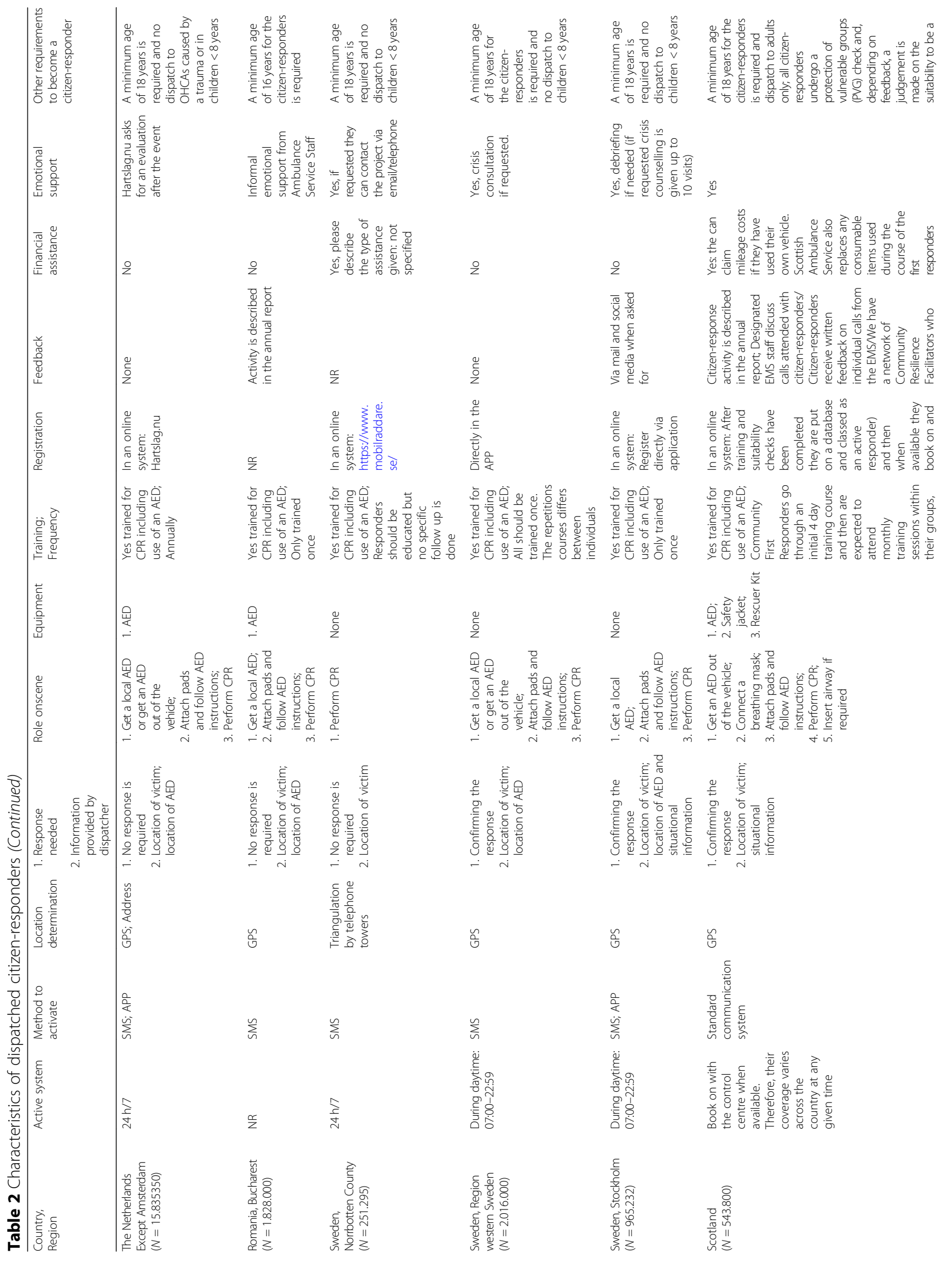




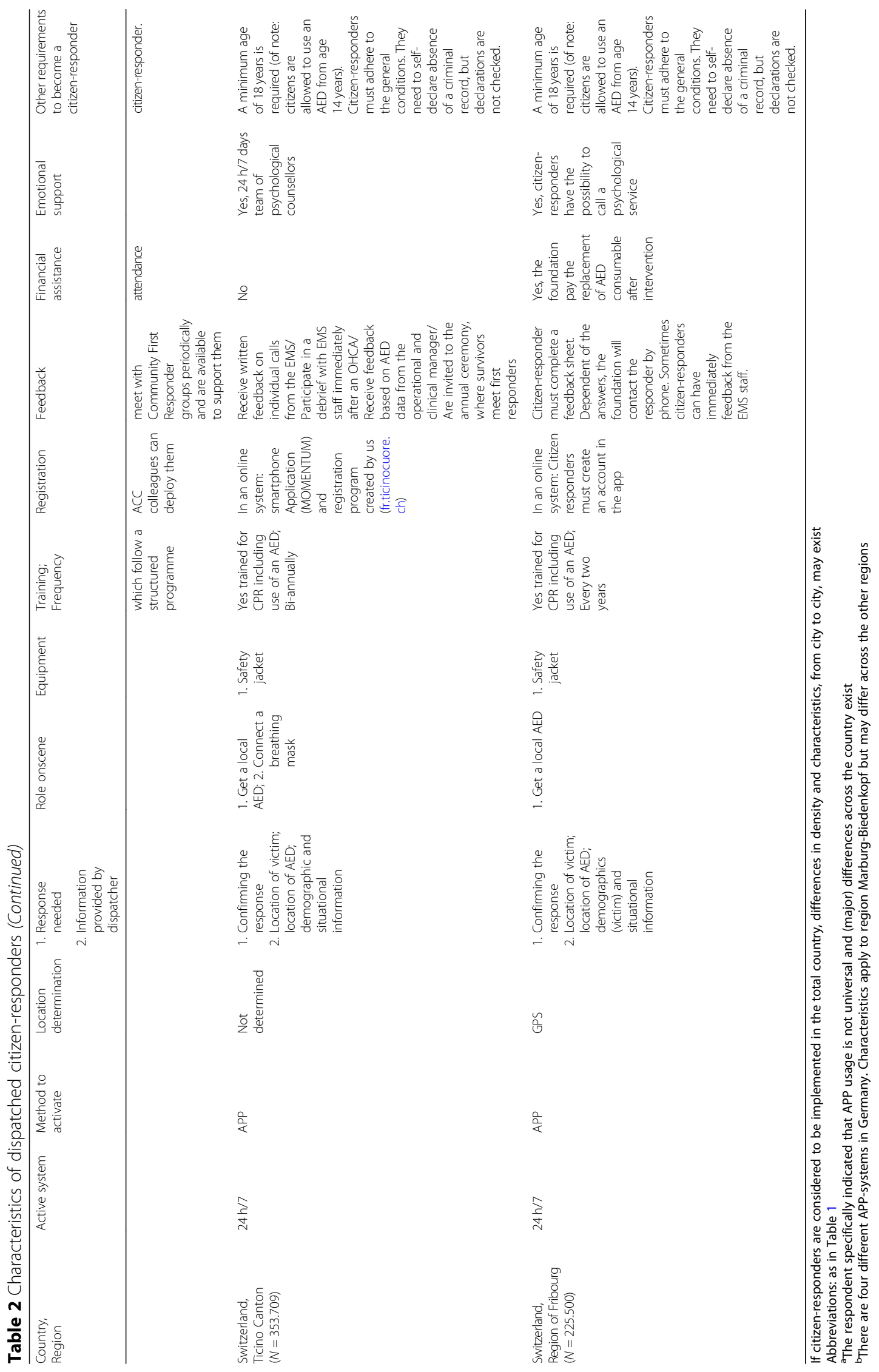




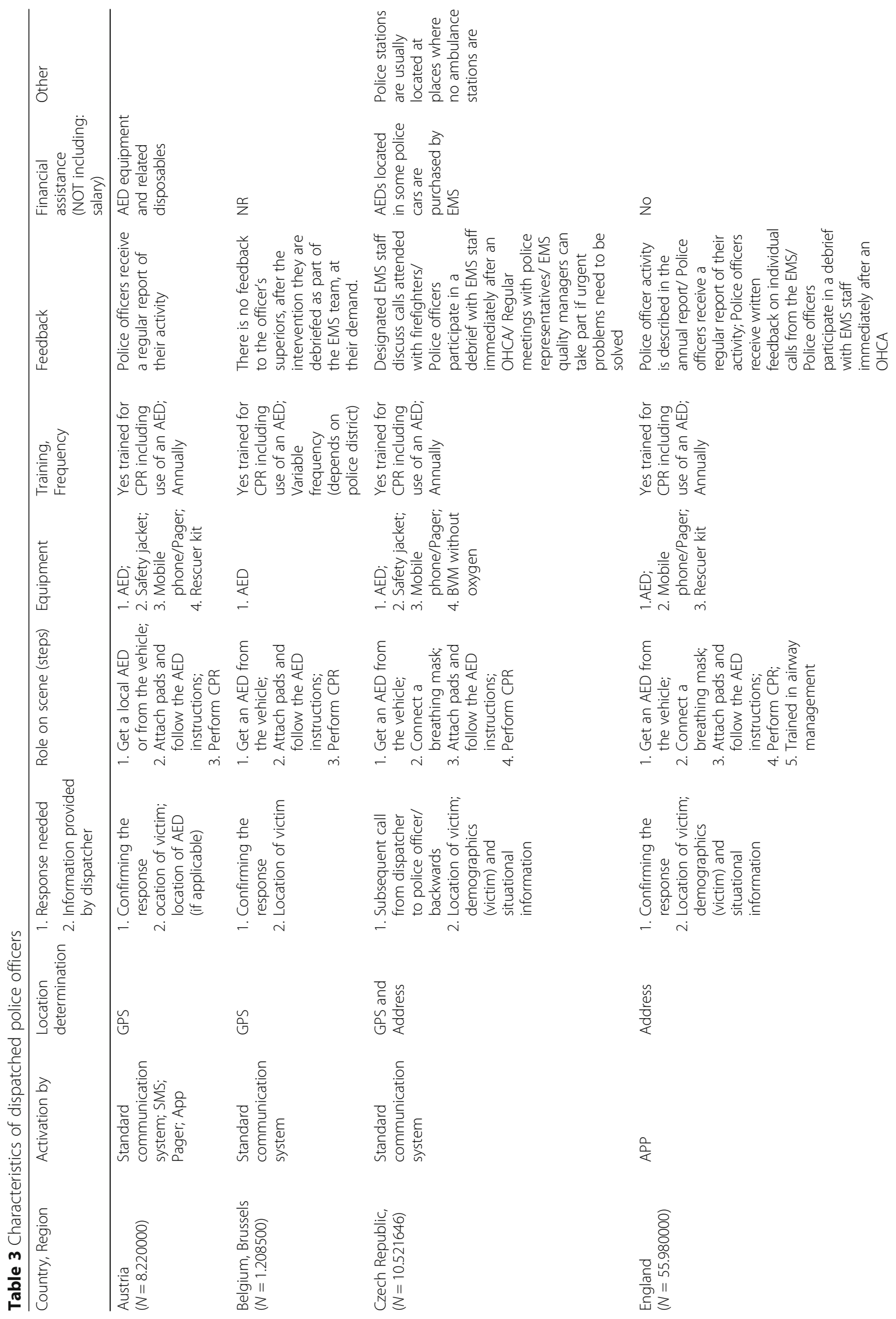




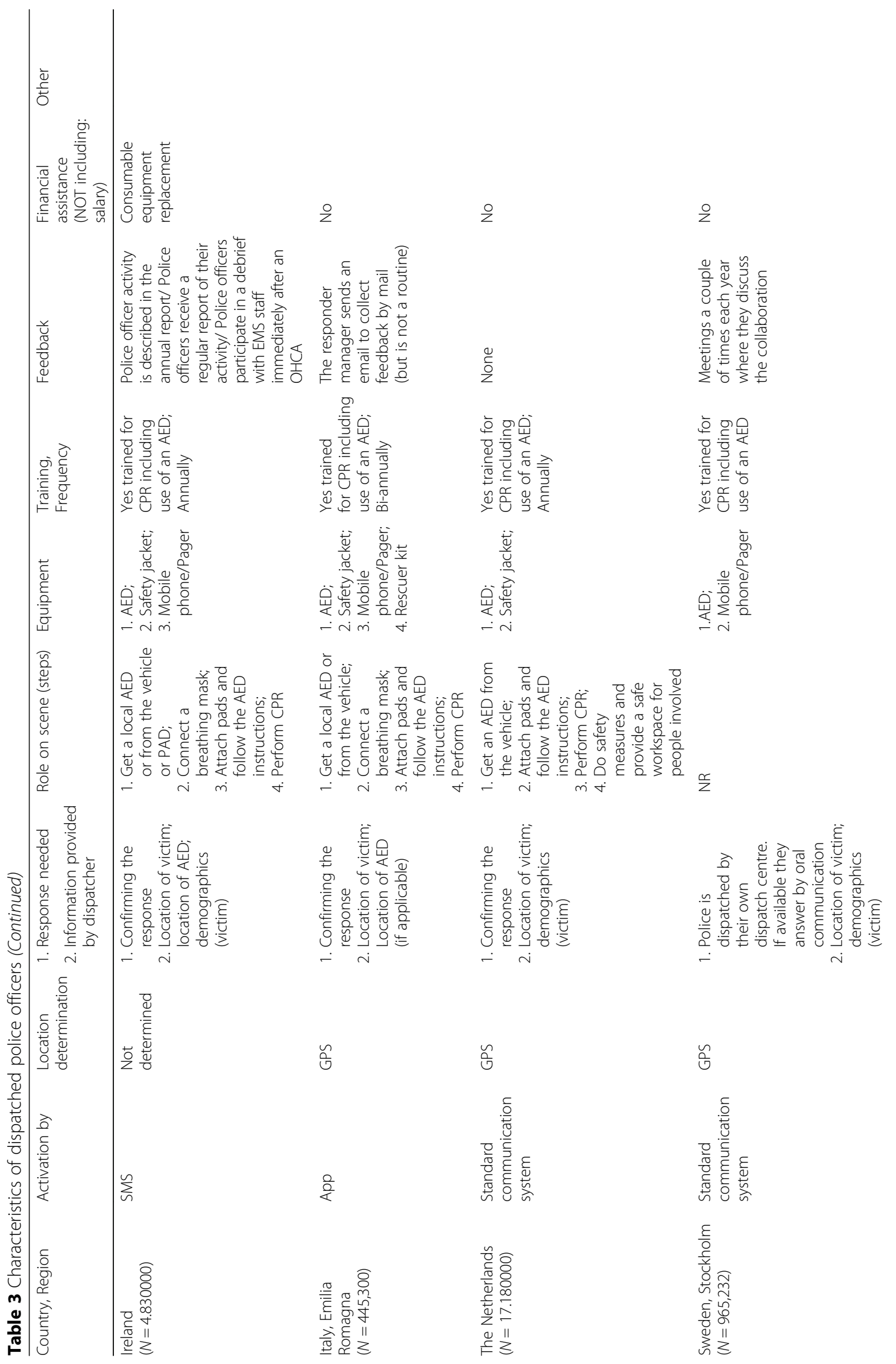




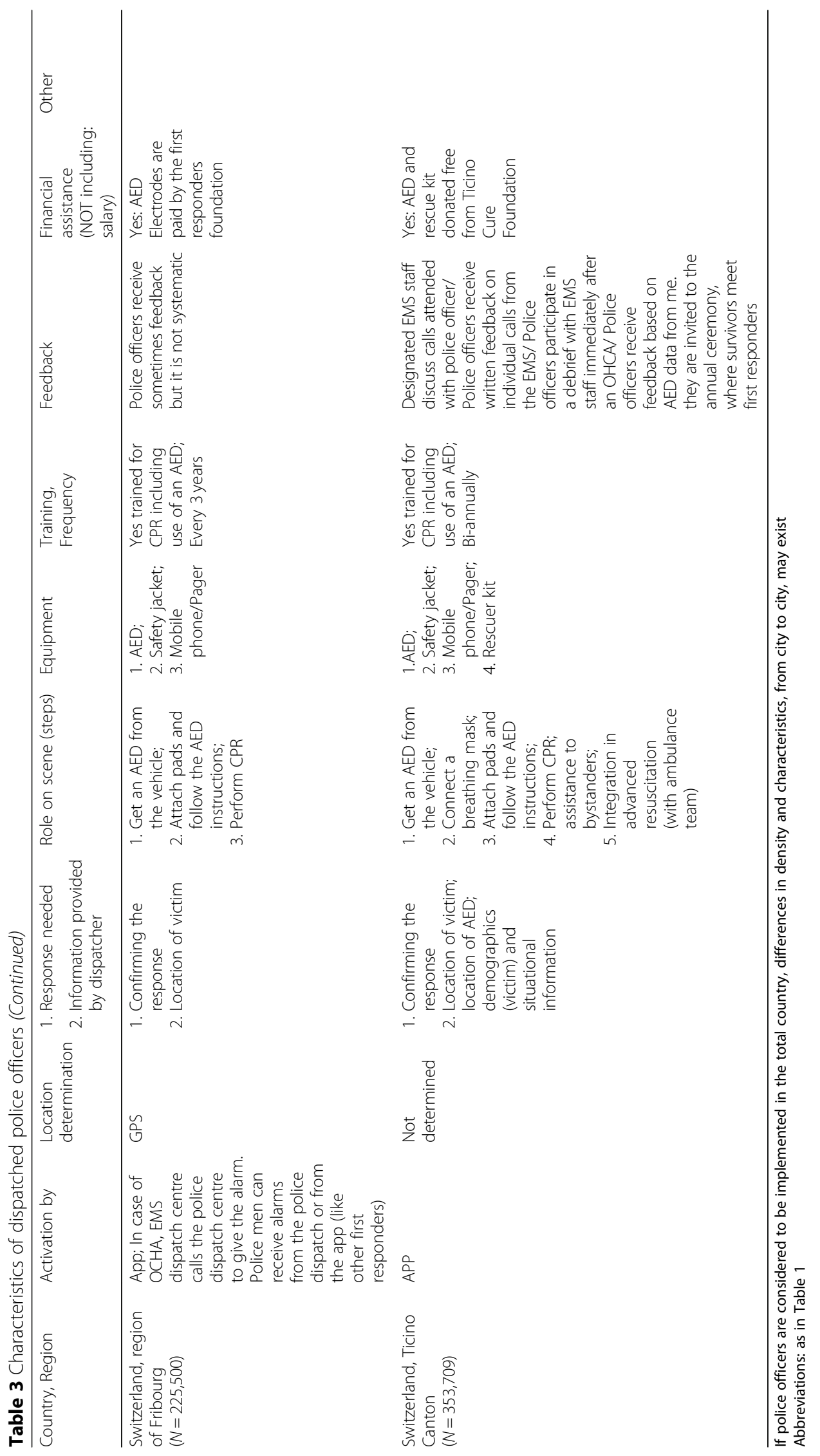


ambulance service on an EMS-owned database. Several countries (Denmark: region Zealand and Southern Denmark, Czech Republic, Ireland and Switzerland) require absence of a criminal record (or of a criminal conviction of significance) in order to be able to register as a citizen-responder.

\section{National and regional policies}

Policies relating to the implementation of FR-systems are described on national or regional level, or both (Table 4). National policies may apply to the total FRsystem or may be limited to one FR type only (Additional file 1: Table S2).

\section{Future implementations of FR-systems in Europe}

As shown in Fig. 2b, some countries did not dispatch FRs to attend an OHCA at the time of the survey. Respondents from Bosnia-Herzegovina, Croatia, Cyprus, Estonia, Greece, France, Iceland, and Serbia were not aware of plans to introduce FR-systems to their countries in the short term. Specific reasons for this are described in Additional file 1: Table S2, and include: (1) implementation of FRs is not a subject of interest or not considered as a priority; (2) there is a lack of a legal background definition for FRs, and (3) there are some local unmapped AEDs, but the location of these AEDs is not available to the dispatch centre.

At the time of our survey, in Malta, government and non-governmental organisations were negotiating to implement a FR-system. In Spain, at least two regional EMS-systems were recruiting citizens to respond to OHCA. In Italy, there were indications that the Province of Pavia would begin implementing FR-systems within a few months (Additional file 1: Table S2).

\section{Discussion}

Key findings

Our study shows the variety of FR-systems that have developed in Europe to expedite provision of good quality CPR and defibrillation in case of an OHCA. These FRsystems have either been implemented nationwide or regionally, and development is primarily influenced by local initiatives, circumstances and opportunities. Policies regarding FRs are commonly implemented on a regional level, even if a national policy exists. This has resulted in a wide variety of FR-systems both between and within countries. Even in countries that do not have FR-systems in place, local and national initiatives to implement FR-systems are being developed.

\section{The need for FR-systems}

The evidence for the benefits of early defibrillation are clear, therefore it may be suggested that increasing the number of AEDs available should be sufficient to improve OHCA survival. However, an increased number of AEDs alone is unlikely to improve survival in a costeffective manner, as demonstrated by an Irish Health Technology Assessment which calculated that an investment of $€ 105$ million in AED purchase would yield - at best - an additional 10 lives saved per year [23]. Rather, the strategic deployment of AEDs by CPR-competent FRs may be an important link in the Chain of Survival $[12,16,17]$, as acknowledged in the most recent European Resuscitation Guidelines [18].

We observed that, even in countries with a national FR-policy, the organisation of FR-systems is often managed by regional EMS. The design of FR-systems is thus commonly influenced by local circumstances and by what is available. For instance, in Slovenia, a FR-system with voluntary firefighters was chosen because of the extensive network of volunteer fire brigades across all villages. Although there is interest from police officers to be part of this FR-system, the network of police patrols in Slovenia is less dense than that of fire fighters and, therefore, police are not included in the FR-system.

\section{Important aspects of FR-systems}

It is unlikely that a "one size fits all" FR-system in Europe can be implemented. However, by combining results from this study with previous studies, some important aspects of FR-systems have been identified.

First, FR type and number of dispatched FR types within one FR-system may be important. In our study, firefighters featured highly as FR types and previous research has demonstrated their role in OHCA-survival [11, 12, 24, 25]. FR-systems involving police officers and/ or dispatched citizen-responders are very promising, but more research is needed [14, 26, 27]. In certain regions, multiple FR types in one FR-system exist. So far, only limited evidence towards the effectiveness of having multiple FR-types is available. A study performed in the Netherlands by Zijlstra and colleagues showed that, while the contribution of citizen-responders was limited by the strong involvement of other FRs and their competing contribution to OHCA care, it was estimated that, without the citizen-responders, $7.3 \%$ of patients would not have received a first shock within 6 min [16]. Also, in Sweden, a study comparing additional dispatch of CPR trained firefighters and police officers equipped with AEDs to a control group where only EMS was dispatched showed that dispatching these two FRs was associated with a significant increase in 30-day survival [27]. However, more research is needed.

Second, the method of alerting FRs matters. Our results showed that firefighter and police FRs are commonly alerted by their own standard dispatch system, and previous evidence highlighted the benefit of direct communication between the EMS and firefighter and 
Table 4 Analysis of national policies relating to First Responders, per country

\begin{tabular}{lll}
\hline Country & $\begin{array}{l}\text { Implementation: } \\
\text { National or } \\
\text { Regional }\end{array}$ & Short description of policy \\
\hline Austria & Regional & Not reported \\
Czech & $\begin{array}{l}\text { National and } \\
\text { Republic } \\
\text { regional }\end{array}$ & $\begin{array}{l}\text { There is a national policy related to professional FRs (firefighters/police officers). This policy is very general (e.g. CPR } \\
\text { training requirement). All 14 regional EMS organizations in the country have been using professional FRs to some } \\
\text { extent. They differ a little across the areas to optimise the best strategy per region. Only } 1 \text { EMS has also introduced } \\
\text { a mobile app for alerting FRs, incl. Both off-duty EMS personnel and citizen FRs. Citizen FRs need to have a valid } \\
\text { BLS/AED course certificate. }\end{array}$
\end{tabular}

Denmark National and Denmark has a strategy of engaging the community in saving lives after OHCA and succeeded in tripling the regional bystander rate and the survival after OHCA within the last 15 years. New programs dispatching citizen-responders through a smart phone application has been implemented within the last few years.

The government of Denmark supports the 10 steps of increasing survival after OHCA defined by the Global Resuscitation Alliance, GRA: https://www.globalresuscitationalliance.org/wp-content/pdf/acting_on_the_call.pdf and has a national "Resuscitation Academy" program working to implement the 10 steps in the five Danish regional EMS organizations.

Denmark also has some experience including professional fire fighters and police at OHCA already and expects to strengthen this collaboration within the next years.

Ireland National and regional

Italy Regional

Luxembourg Regional

Netherlands National and regional

Norway National and regional

Portugal Regional

Slovenia National and regional
The National Ambulance Service has a history of FR involvement which predates the 2000s. General practitioners have been acting as FRs in selected parts of the country since the early 1990s. The first formal recommendation to support the development of first responders appears in the following national document which was produced by our Department of Health:

"Reducing the Risk: A Strategic Approach. Report of the Task Force on Sudden Cardiac Death (2006)".

The National Ambulance Service has policy and procedure documents to support first responder involvement in cardiac arrest response. Ireland is in the process of developing a national OHCA strategy, which will include further specific recommendations to further the development of first response in Ireland.

Law in Italy: Citizen trained in BLS are allowed to start CPR and to use an AED; citizens not trained can start CPR and use an AED accordingly to the law that regulates the "state of necessity" in emergency situations.

The law in Italy for FRs and untrained lay people is a barrier to diffusion of bystander intervention.

Some regions in Italy (Region of Emilia Romagna) implemented FRs. FRs will become more common in Italy in other regions (e.g., Province of Pavia).

Since July 1, 2018 Luxembourg is completely reorganised in only one EMS organisation for the country. Luxembourg has a FR system working in 56 out of 102 municipalities. This service is provided exclusively by volunteer firefighters because they are "in the system" and thus quite easily reachable. There are different modalities according to local circumstances. Either the FR get to the scene by their own means (when they have the equipment in their car) or they meet at the fire station to get their equipment before going to the scene. In Luxembourg, for the moment, there are only firefighters acting as "organized" FRs. Police is more reluctant to participate and there is no citizen-responder system.

There is a mandatory training in CPR for school children since 2017 and the Luxembourg Resuscitation Council strives to train as many as possible persons in elementary CPR (hands-only) on a voluntary basis.

In the Netherlands, a national policy regarding citizen-responders was published, whereas the requirements for firefighters and police officers are described on regional level only.

Regarding the implementation of AEDs and citizen-responders, the first policy was written in 2002. The reason to involve no citizen-responders in the capital Amsterdam is the proximity of police officers and firefighters (always shorter than 6 min to OHCA victim).

The Directory of health is working on policies and guidelines for FRs, including what a FR is, who can be called a FR and legal implications and concerns.

There are 16 dispatch centres in Norway and they are all relating to firefighters as FRs in different ways

At the present moment, private investors are spreading AED programs with the main purpose to have a system with FRs in the event of an OHCA. In one region (21.000 people of 506.000) of Lisbon, police officers have been trained in BLS and AED. Portugal is in a preliminary process regarding the start of FRs.

In Slovenia, only voluntary fire fighters are implemented as FRs. This is due to a very extended network of firefighters brigades in Slovenia (literally, every village in Slovenia has a voluntary firefighters brigade). At the present moment, 35.000 volunteer fire fighters are organized in approximately 1500 fire fighters brigades. This number exceeds the number of policemen by six-times (approximately 5500 policemen). Voluntary firefighters in Slovenia are well organized and equipped (vehicles, communication, rescue equipment, etc.).

On the other hand there is no nationwide strategy "how to organize FRs". The Slovenian government released the document/regulation which basic conditions must be fulfilled to become a FR (skills, equipment, etc.). But the organization of FR is left to the local EMS. The local EMS firstly considers the need of first responders (especially in remote areas). Afterwards the local fire fighters brigade will be contacted to participate in a FR system (there is no obligation). Therefore, there are areas in Slovenia without FRs.

Policemen patrol network is scarce compared to the fire fighters (there is interest by policemen to be also a part of a FR system). 
Table 4 Analysis of national policies relating to First Responders, per country (Continued)

\begin{tabular}{|c|c|c|}
\hline Country & $\begin{array}{l}\text { Implementation: } \\
\text { National or } \\
\text { Regional }\end{array}$ & Short description of policy \\
\hline England & $\begin{array}{l}\text { National and } \\
\text { regional }\end{array}$ & $\begin{array}{l}\text { In England, ambulance trusts are responsible for local implementation, but there is an overarching Governance } \\
\text { Framework. }\end{array}$ \\
\hline Sweden & Regional based & $\begin{array}{l}\text { Strategies or policies recommending establishment or the development of FRs in Sweden is lacking. Policies are } \\
\text { regional. }\end{array}$ \\
\hline Switzerland & Regional based & $\begin{array}{l}\text { In Switzerland all health issues (except the management of epidemics and disasters) are left to the cantons. It } \\
\text { follows that with } 26 \text { cantons, there are } 26 \text { different health laws. Since the FR network is still considered ancillary to } \\
\text { the EMS, there is no health law that takes this into account. This is the reason why there are so many different } \\
\text { approaches (even inside the cantons). Only a few cantons have created a structure for the purpose of uniformly } \\
\text { managing the FRs. Leading position and pioneer is Canton Ticino (https://www.ticinocuore.ch/en). } \\
\text { The Swiss Resuscitation Council is working on a national strategy against OHCA. }\end{array}$ \\
\hline
\end{tabular}

AED Automatic External Defibrillator, CPR Cardiopulmonary Resuscitation, EMS Emergency Medical Services, ERC European Resuscitation Council, FR Firstresponder, OHCA Out Of Hospital Cardiac Arrest

police FRs [28, 29]. A mobile phone alert is often used to alert citizen-responders, but only a few regions use a mobile phone alert to alert other FR types (i.e., firefighters and police officers). In a study carried out in Switzerland, all FR types (firefighters, police, citizenresponders) were alerted by either an app or textmessage system (both considered as a mobile phone alert) [15]. The app-system, when compared to a textmessage system, was found to be highly efficient in the deployment of FRs, significantly reducing the time to initiation of CPR and increasing survival rates [15].

Third, our study showed that the response capabilities of FRs should be considered. In the Czech Republic, firefighters were dispatched only in rare cases because they share locations with the EMS. Another example regarding response capabilities includes: in several countries there is no dispatch to children $<8$ years by citizenresponders. Although this applies to a minority of the OHCA population, it should be taken into account. Also, the distinction between volunteer and professional FRs may have an impact on FR engagement and response. Another example includes Slovenia where the local EMS determines the need for FRs, and requests local volunteer firefighters to become FRs. As this strategy depends on local firefighter interest, there are still areas in Slovenia without FRs.

Fourth, our study showed that frequent CPR training is a feature of most FR-systems, as would be expected. Previous research has highlighted the superiority of off-duty medical professionals over laypersons [30] and more recent studies have shown the positive impact of trained citizenresponders on neurological outcomes [31]. Some regions allow citizen-responders to register as FRs without validating CPR-training (e.g., Denmark: Capital region and Central region), whereas CPR training is mandatory in two other regions in Denmark (Region Zealand and Region Southern Denmark). However, in the two regions where CPR training is not mandatory, CPR training is strongly recommended. Also, in Denmark, large-scale population-based CPR training is common, and the positive impact of populationbased CPR training has most recently been demonstrated by Kobayashi and colleagues in Japan [32]. Finally, improved survival after implementation of FR-systems is unlikely to occur unless all links in the Chain of Survival are working. Hence, improvements in bystander-CPR should receive high priority.

\section{Future implementation of FR-systems}

We hypothesise that the general tendency in Europe towards more widespread implementation of FR-systems will increase OHCA survival rates. At present, FRimplementation may not be a priority for every country and difficulties in the legal definition of FRs may contribute to this. However, lack of national policies may not be an impediment to local development. For instance, in Greece, small local initiatives already exist in the absence of a national policy. In Croatia, local initiatives are developed, including nurses on motorbikes and CPR-trained firefighters and police officers equipped with AEDs. However, these initiatives are not currently connected to the EMS to be dispatched and this may limit their rapid response. In other countries and regions, while there is interest, local AEDs are not registered; this may also delay implementation of an effective FR-system. These developments highlight that FRsystems are strongly driven by local initiative and local capabilities. The need to allow flexibility in how FRsystems are implemented locally is likely to be an important consideration in ensuring the sustainability of FR-systems into the future.

\section{Strengths and limitations}

To the best of our knowledge, this study provides the most comprehensive overview of first response in Europe to date. While heterogeneity in FR-systems is a key finding, common themes have been identified that provide a basis for understanding the development of FRsystems at a European level. It is acknowledged that a 
convenience sampling method was used to recruit respondents, but the sample was drawn from participants in well-established European networks that have an active interest in OHCA.

A limitation of this study is that, in countries/regions considered as being covered by a specific FR-system, it was not feasible to estimate the density of FRs (and differences, from city to city, may exist). Also, it was not possible to relate different FR-systems to differences in survival rates. However, this study has highlighted a unique element of the Chain of Survival which should be considered in any further studies of OHCA epidemiology.

When a FR-system is being developed, it is important to analyse response times in order to confirm that the system actually contributes to early CPR and early defibrillation, using measured effects. Only then in the long run, the cost and effort of maintaining such a FR-system will remain accepted in the community.

\section{Conclusions}

At present, more than half of European countries dispatch FRs after a suspected OHCA. Policies relating to FRs are mostly managed by local EMS, leading to a wide variation between and within countries. Even in countries that do not have existing FR-systems, many have local initiatives and future plans for FR-system implementation. The willingness of people to volunteer their time and skills to provide a first response to OHCA has led to the development of a variety of national and local solutions, and has created a new paradigm within the Chain of Survival that needs to be researched and evaluated more extensively. Areas for future research include: identifying the most effective methods of FR dispatch; identifying FR-systems that most strongly influence survival; assessing the effect of adding a FR type in an existing FR-system; and understanding what motivates a volunteer to become a FR and what sustains that motivation. The diverse findings of our study reflect the diversity in circumstances across various European regions and suggest that it is unlikely that there will be a 'one size fits all' FR-system across Europe. Rather, an overall European policy that advises on the critical requirements for effective FR may be of benefit.

\section{Supplementary information}

Supplementary information accompanies this paper at https://doi.org/10. 1186/s13049-019-0689-0.

Additional file 1. Respondents and survey definitions.

\section{Abbreviations}

AED: automated external defibrillator; ARREST: Amsterdam Resuscitation Studies; CPR: Cardiopulmonary resuscitation; EMS: emergency medical service; ERC: European Resuscitation Council; FR: first responder; OHCA: outof-hospital cardiac arrest

\section{Acknowledgements}

We greatly appreciate the contributions of Paulien Homma (MSc), Remy Stieglis (MSc) and Sanne Brands (MSc) of the Academic Medical Center (Amsterdam, The Netherlands) for piloting the survey and to the data collection. Also, we are greatly indebted to Patrick Sulzgruber (MD, PhD from Austria), Stephanie Leckey (BSc, from Northern Ireland), Cristina Granja (MD, $\mathrm{PhD}$ ) and Tiago Amaral (MSc) from Portugal), Ari Salo (MD, PhD from Finland), Linn Andelius (MD, from Denmark), Mark Biancardia (MD, from Malta), Veronika Reinhard (MD, from Estonia), Koen Monsieurs (MD, PhD), David Yansenne, Pierre Mols (MD, PhD) and Bernard Kreps (MD, PhD) (from Belgium), Marios loannidis (MD, PhD, from Cyprus), Violetta Raffay (MD, PhD, from Serbia), Emma Scott and Nicola Dunbar (from the United Kingdom), Enrico Baldi (MSc, from Italy), Vidar Magnusson (MD, MBA) and Hildigunnur Svavarsdottir (PhD) (from Iceland), Hajriz Alihodžić (MD, PhD, from Bosnia Herzegovina), Fernando Rosell Ortiz (MD, PhD from Spain), Nagy Enikő (from Hungary), Pascal Stammet (MD, PhD from Luxembourg), Andrej Markota (MD, PhD) and Janez Strnad (MD, PhD) (from Slovenia), Craig Hunter (from Scotland), Grzegorz Cebula (MD, PhD from Poland), Michael Müller (MD, $\mathrm{PhD}$ ), Dennis Rupp and Erich Wranze (MD, PhD) (from Germany) and Xavier Jouven (MD, PhD, from France) for their cooperation and data collection. Also, we would like to thank all other respondents and national resuscitation councils who so generously shared their expert opinion and knowledge to make this study possible.

\section{Authors' contributions}

IO: study protocol, data collection, data analyses, writing the manuscript. SM: data collection, data analyses, writing the manuscript. IT: data collection, revision of manuscript. MJ: data collection, revision of manuscript. FS: data collection, revision of manuscript. MR: data collection, revision of manuscript. AT: data collection, revision of manuscript. DC: data collection, revision of manuscript. FF: data collection, revision of manuscript. SB: data collection, revision of manuscript. RK: data collection, revision of manuscript. HT: supervision, revision of manuscript. MB: study protocol, supervision, revision of manuscript. "All authors read and approved the final manuscript".

\section{Funding}

This project/work has received funding from the European Union's Horizon 2020 research and innovation programme under acronym ESCAPE-NET, registered under grant agreement No 733381. Dr Tan and Dr Blom were supported by Dutch Heart Foundation (CVON 2018-30 Predict2).

\section{Availability of data and materials}

The datasets used and/or analysed during the current study are available from the corresponding author on reasonable request.

\section{Ethics approval and consent to participate}

Informed consent for using the contact details of the participants was sought and provided. This study is part of the ESCAPE-NET study which has been approved by the Institutional Review Board of Amsterdam UMC.

\section{Consent for publication}

Not applicable.

\section{Competing interests}

The authors declare that they have no competing interests.

\section{Author details}

${ }^{1}$ Department of Clinical and Experimental Cardiology, Heart Center, Amsterdam Cardiovascular Sciences, Amsterdam UMC, Department of Cardiology, Heart Center, Academic Medical Center, University of Amsterdam, Meibergdreef 9, 1105, AZ, Amsterdam, The Netherlands. ${ }^{2}$ Department of General Practice, National University of Ireland Galway and National Ambulance Service, Dublin, Ireland. ${ }^{3}$ Norwegian National Advisory Unit on Prehospital Emergency Medicine (NAKOS), Oslo, Norway. ${ }^{4}$ Centre for Resuscitation Science, Department for Medicine, Karolinska Institutet, Stockholm, Sweden. ${ }^{5}$ Department of Anaesthesia, Intensive Care and Emergency Medical Services, Ospedale Maggiore, Bologna, Italy. ${ }^{6}$ Emergency Medical Services of the Hradec Kralove Region, Czech Republic and 
Department of Anaesthesiology and Intensive Care Medicine, University Hospital Hradec Králové, Hradec Králové, Czech Republic. 'Department of Emergency Medicine, "Grigore T. Popa" University of Medicine and Pharmacy, lasi, Romania. ${ }^{8}$ Department of Cardiology, Copenhagen University Hospital Gentofte, Hellerup, Denmark. ${ }^{9}$ Emergency Medical Services Copenhagen, University of Copenhagen, København, Denmark. ${ }^{10}$ Netherlands Heart Institute, Utrecht, The Netherlands.

Received: 2 August 2019 Accepted: 20 November 2019

Published online: 16 December 2019

\section{References}

1. Holmgren C, Bergfeldt L, Edvardsson N, et al. Analysis of initial rhythm, witnessed status and delay to treatment among survivors of out-of-hospital cardiac arrest in Sweden. Heart. 2010;96(22):1826-30.

2. Grasner JT, Lefering R, Koster RW, et al. EuReCa ONE-27 nations, ONE Europe, ONE registry: a prospective one month analysis of out-of-hospital cardiac arrest outcomes in 27 countries in Europe. Resuscitation. 2016;105: 188-95.

3. Viereck S, Palsgaard Moller T, Kjaer Ersboll A, Folke F, Lippert F. Effect of bystander CPR initiation prior to the emergency call on ROSC and 30day survival-an evaluation of 548 emergency calls. Resuscitation. 2017;111:55-61.

4. Kragholm K, Wissenberg M, Mortensen RN, et al. Bystander efforts and 1year outcomes in out-of-hospital cardiac arrest. N Engl J Med. 2017;376(18): $1737-47$.

5. Blom MT, Beesems SG, Homma PC, et al. Improved survival after out-ofhospital cardiac arrest and use of automated external defibrillators. Circulation. 2014;130(21):1868-75.

6. Hansen CM, Kragholm K, Granger CB, et al. The role of bystanders, first responders, and emergency medical service providers in timely defibrillation and related outcomes after out-of-hospital cardiac arrest: results from a statewide registry. Resuscitation. 2015;96:303-9.

7. Kiyohara K, Nishiyama C, Matsuyama T, et al. Out-of-hospital cardiac arrest at home in Japan. Am J Cardiol. 2019;123:1060-8

8. Sondergaard KB, Wissenberg M, Gerds TA, et al. Bystander cardiopulmonary resuscitation and long-term outcomes in out-of-hospital cardiac arrest according to location of arrest. Eur Heart J. 2018:40(3):309-18.

9. Waalewijn RA, de Vos R, Tijssen JG, Koster RW. Survival models for out-ofhospital cardiopulmonary resuscitation from the perspectives of the bystander, the first responder, and the paramedic. Resuscitation. 2001;51(2): $113-22$

10. Hollenberg J, Riva G, Bohm K, et al. Dual dispatch early defibrillation in outof-hospital cardiac arrest: the SALSA-pilot. Eur Heart J. 2009;30(14):1781-9.

11. Hasselqvist-Ax I, Nordberg P, Herlitz J, et al. Dispatch of firefighters and police officers in out-of-hospital cardiac arrest: a Nationwide prospective cohort trial using propensity score analysis. J Am Heart Assoc. 2017;6(10):15.

12. Nordberg $P$, Hollenberg J, Rosenqvist $M$, et al. The implementation of a dual dispatch system in out-of-hospital cardiac arrest is associated with improved short and long term survival. Eur Heart J Acute Cardiovasc Care. 2014;3(4):293-303

13. Moore MJ, Hamilton AJ, Cairns KJ, et al. The Northern Ireland public access defibrillation (NIPAD) study: effectiveness in urban and rural populations. Heart. 2008;94(12):1614-9.

14. Ringh M, Rosenqvist M, Hollenberg J, et al. Mobile-phone dispatch of laypersons for CPR in out-of-hospital cardiac arrest. N Engl J Med. 2015; 372(24):2316-25

15. Caputo ML, Muschietti S, Burkart R, et al. Lay persons alerted by mobile application system initiate earlier cardio-pulmonary resuscitation: a comparison with SMS-based system notification. Resuscitation. 2017;114: 73-8.

16. Zijlstra JA, Stieglis R, Riedijk F, Smeekes M, van der Worp WE, Koster RW. Local lay rescuers with AEDs, alerted by text messages, contribute to early defibrillation in a Dutch out-of-hospital cardiac arrest dispatch system. Resuscitation. 2014;85(11):1444-9.

17. Pijls RW, Nelemans PJ, Rahel BM, Gorgels AP. A text message alert system for trained volunteers improves out-of-hospital cardiac arrest survival. Resuscitation. 2016;105:182-7.

18. Monsieurs KG, Nolan JP, Bossaert LL, et al. European resuscitation council guidelines for resuscitation 2015: section 1. Executive summary. Resuscitation. 2015;95:1-80
19. Empana JP, Blom MT, Bttiger BW, et al. Determinants of occurrence and survival after sudden cardiac arrest-a European perspective: the ESCAPE-NET project. Resuscitation. 2018;124:7-13.

20. Blom MT, van Hoeijen DA, Bardai A, et al. Genetic, clinical and pharmacological determinants of out-of-hospital cardiac arrest: rationale and outline of the AmsteRdam resuscitation studies (ARREST) registry. Open Heart. 2014;1(1):e000112.

21. Ringh M, Hollenberg J, Palsgaard-Moeller T, et al. The challenges and possibilities of public access defibrillation. J Intern Med. 2018;283(3):238-56.

22. Guidelines 2000 for cardiopulmonary resuscitation and emergency cardiovascular care. Part 4: the automated external defibrillator: key link in the chain of survival. The American Heart Association in collaboration with the International Laison Committee on Resuscitation. Circulation. 2000;102(1 Suppl):102:I-60-I-76.

23. Moran P, Teljeur C, Masterson S, O'Neill M, Harrington P, Ryan M. Costeffectiveness of a national public access defibrillation programme. Resuscitation. 2015;91:48-55.

24. Shuster M, Keller JL. Effect of fire department first-responder automated defibrillation. Ann Emerg Med. 1993;22(4):721-7.

25. Smith KL, Peeters A, McNeil JJ. Results from the first 12 months of a fire first-responder program in Australia. Resuscitation. 2001;49(2):143-50.

26. Baekgaard JS, Viereck S, Moller TP, Ersboll AK, Lippert F, Folke F. The effects of public access defibrillation on survival after out-of-hospital cardiac arrest: a systematic review of observational studies. Circulation. 2017;136(10):954-65.

27. Hasselqvist-Ax I, Nordberg P, Herlitz J, et al. Dispatch of firefighters and police officers in out-of-hospital cardiac arrest: a nationwide prospective cohort trial using propensity score analysis. J Am Heart Assoc. 2017;6(10): e005873.

28. White RD, Bunch TJ, Hankins DG. Evolution of a community-wide early defibrillation programme experience over 13 years using police/fire personnel and paramedics as responders. Resuscitation. 2005;65(3):279-83.

29. Myerburg RJ, Fenster J, Velez M, et al. Impact of community-wide police car deployment of automated external defibrillators on survival from out-ofhospital cardiac arrest. Circulation. 2002;106(9):1058-64.

30. Nord A, Svensson L, Karlsson T, Claesson A, Herlitz J, Nilsson L. Increased survival from out-of-hospital cardiac arrest when off duty medically educated personnel perform CPR compared with laymen. Resuscitation. 2017;120:88-94

31. Ko SY, Ro YS, Shin SD, Song KJ, Hong KJ, Kong SY. Effect of a first responder on survival outcomes after out-of-hospital cardiac arrest occurs during a period of exercise in a public place. PLoS One. 2018;13(2):e0193361.

32. Kobayashi D, Kitamura T, Kiyohara K, et al. Cardiopulmonary resuscitation performed by off-duty medical professionals versus laypersons and survival from out-of-hospital cardiac arrest among adult patients. Resuscitation. 2019;135:66-72.

\section{Publisher's Note}

Springer Nature remains neutral with regard to jurisdictional claims in published maps and institutional affiliations.

Ready to submit your research? Choose BMC and benefit from:

- fast, convenient online submission

- thorough peer review by experienced researchers in your field

- rapid publication on acceptance

- support for research data, including large and complex data types

- gold Open Access which fosters wider collaboration and increased citations

- maximum visibility for your research: over $100 \mathrm{M}$ website views per year

At $\mathrm{BMC}$, research is always in progress.

Learn more biomedcentral.com/submission 